\title{
Higher Education and the Exponential Rise of Science: Competition and Collaboration
}

\author{
JUSTIN J.W. POWELL
}

\begin{abstract}
How we collaborate and compete to find solutions to the problems and challenges of our age vastly impacts our individual and group success and well-being. Interdependent, the institutions of education and science have dramatically expanded. Today, scientists in nearly all countries contribute to our shared stores of knowledge, with research universities the driving force behind unexpected pure exponential growth in scientific production. Competition-regional, national, organizational, and individual-has become more potent-with performance measures, comparative indicators, and formal evaluations continuously generated and used in decision-making. Simultaneously, collaboration across institutional, disciplinary, organizational, and cultural boundaries expands the possibilities of discovery and produces the most influential science. Competition and collaboration at the nexus of higher education and science demand enhanced attention as they shape the future of scientific innovation and production, with its understudied yet increasingly incontrovertible effects on individuals and societies.
\end{abstract}

\section{INTRODUCTION}

Whether between regions, nations, social groups, or individuals, how we collaborate and compete to find solutions to the problems and challenges of our age vastly impacts our individual and group success and well-being. More than ever before, we seek answers to the critical questions of survival, health, and flourishing in the twin panaceas of (higher) education and science. These interdependent institutions have dramatically expanded. What just a century ago was the province of a tiny elite is now accessible to the majority. Indeed, today we live in "schooled societies" (Baker, 2014) in which most valued positions and life chances of individuals are increasingly decided by the level and quality of their educational experiences. Yet stratification patterns

Emerging Trends in the Social and Behavioral Sciences.

Robert A. Scott and Marlis Buchmann (General Editors) with Stephen Kosslyn (Consulting Editor).

(C) 2018 John Wiley \& Sons, Inc. ISBN 978-1-118-90077-2. 
reflect persistent disparities in group educational attainment and access to science-producing resources.

The phenomenal rise in organized learning has had unforeseen and extraordinary consequences also in the realm of science, such as exponential growth in scientific production. Science more than ever determines how we (attempt to) solve global social and environmental problems as well as the scale and scope of growth in economies increasingly based on information, knowledge, and technology. Thus, the demand for higher education and science in countries around the world has never been greater. Steadily increasing educational achievement and attainment levels worldwide and expanded scientific capacity have generated many benefits to society, including more knowledgeable citizens, productive economies, and enhanced longevity, but complex challenges abound.

Throughout the world, the demand for higher education led to unprecedented investments, which improved science capacity. Indeed, universities provide robust infrastructure and innovation-oriented networks, educate scientists across the disciplines, and sustain scientific output. Among other organizational forms that produce most research-extra-university research institutes, government agencies, private companies, and hospitals-research universities have remained the driving force behind the global growth of scientific productivity. They connect all types of knowledge-producing organizations and contribute the majority of scientific publications (Powell \& Dusdal, 2017; Powell, Fernandez et al., 2017; Dusdal, 2018).

Countries invest heavily into scientific output and technological innovation, as advanced knowledge is applied in ever more fields, themselves reshaped by that knowledge, for example, in computing and robotics. Specialization in higher education and science reshapes labor markets, increasingly defined by academic distinctions and occupational boundaries (Baker, 2014). This self-reinforcing evolution of employment segments develops higher education and science through the demand for credentials and expertise. Yet innovative science also calls for enhanced and targeted investments, from diverse sources. In the inexorable race for breakthroughs, difficult choices are necessary. Competition on multiple levels has become more potent. Formal evaluations, performance measures, and comparative indicators are continuously generated. Although imperfect proxies, they become the basis for decision-making, in policy arenas, organizations, research teams, and individual careers.

Simultaneously, collaboration across institutional, disciplinary, organizational, and cultural boundaries expands the possibilities of discovery. Indeed, if competition in this context reflects a learning race to achieve new knowledge, then participation in networks, and interorganizational linkages, with continuous communication and collaborations of different 
sorts, will be crucial to success (Powell, 1998). Scientific collaborations, with the goal to achieve new scientific knowledge (Katz \& Martin, 1997), often begin informally, the result of conversation between researchers meeting in face-to-face situations (Jeong, Choi, \& Kim, 2014). Depending on the field and constellations of scientists in the team, collaborations may be driven by ideas and theories, equipment, resources, or data (Wagner, 2005). Collaboration leads to more influential, often-cited research, especially among scholars in different countries (Katz \& Hicks, 1997; Fortunato et al., 2018) - a key argument for further globalizing the scientific enterprise and recognizing the brain circulation and intercultural teamwork that facilitates recognition and impact across scientific communities (Sugimoto et al., 2017).

As scientists increasingly work in teams, extend their understanding, and compete to discover important ideas, they need to meet, understand, cooperate, and collaborate, doing so for myriad reasons (see Beaver, 2001; Leahey, 2016). In fact, in some fields today, there is no choice, as work becomes so complex that individual scientists cannot achieve meaningful results without collaborating — called the "collaboration imperative" (Bozeman \& Boardman, 2014). A century ago most research papers published in diverse disciplines were written by single authors. Today, the modal paper in the natural and social sciences represents the work of multiple authors, often from different organizational and national contexts. The collective shift toward teamwork in research and the implied specialization extends from fundamental research in the natural and social sciences to the applied world of patents (Mosbah-Natanson \& Gingras, 2013; Wuchty, Jones, \& Uzzi, 2007). Thus, competition and collaboration at the intersection of higher education and science are research topics requiring attention if we hope to understand the present and future of scientific discovery and production, with its understudied yet increasingly incontrovertible effects on individuals and societies.

\section{GLOBALIZING HIGHER EDUCATION AND SCIENCE}

Exponential growth in science production around the world has resulted from rising investments in human capability and especially the worldwide triumph of the research university. Unexpected by founders of bibliometrics (de Solla Price, 1986), who rather thought expansion would reach a saturation level and taper off within decades of the advent of "big science" in the 1960s, we instead find that increased global and local competition, as well as boundary-spanning collaborations of various types, have driven unprecedented scientific advancement and technological innovation (Powell, Fernandez et al., 2017). Systematic estimates of the number of 
peer-reviewed articles cataloged in the Science Citation Index Expanded from 1900 onward show science transformed by unprecedented production (Powell, Baker et al., 2017). Growth in scientific production shows no decline or slowing, with "pure exponential growth" up to today: "Big science" has been replaced by what could be called "global mega-science" as well over a million new peer-reviewed articles-the gold standard of scientific output-are published each year just in the leading journals of the natural sciences and health.

Focusing on articles published in the world-leading journals provides insights into the cutting-edge of fundamental research. Charting global shifts in the scientific "center of gravity" shows changing regional scientific output (Powell, Fernandez et al., 2017). Along with the North American, European countries remain essential players in the scientific arena, with their centuries-old research universities being emulated worldwide. Over the past few decades in East Asia, massive government support in Japan, China, South Korea, and Taiwan, for example, have triggered explosive growth of science capacity and the ensuing production. Researchers have only just begun to explain how and why certain countries have succeeded differentially in expanding their higher education and science capacity and which organizational forms and funding instruments do most to facilitate scientific serendipity as well as long-term impact (Powell \& Dusdal, 2017; Powell, Fernandez et al., 2017).

If competition is now fully global, so too is collaboration, as scientists in nearly all countries contribute to our shared stores of legitimated knowledge. Most often, scientists and scholars conduct their work in increasingly research-oriented universities, which have proliferated around the world, especially since WWII. Indeed, university-based research has risen to become the driving force of science production globally. Despite universities operating successfully in all societies, substantial regional differences in contributing to cutting-edge scientific communication and disciplinary debates continue to exist. This further emphasizes the need for intercultural research collaborations, in particular, across the hemispheres; beyond the extensive links that exist across the global North. Currently, the shifting "center of gravity" away from North America emphasizes the relative decline of the United States as European and Asian countries invest heavily in their national higher education and research capacity. At the same time, cutting-edge knowledge production increasingly relies on building international, intercultural, and interorganizational bridges to facilitate joint learning processes and scholarship recognized by diverse scientific communities. Research and development demands investments not only in individuals within organizations and infrastructures but also-more 
than ever-in the networks, connections, and exchanges that facilitate discoveries.

\section{TRENDS IN AND DRIVERS OF COMPETITION AND COLLABORATION}

The potential of contemporary science cannot be understood and the pathways to its further development charted without examining two contrasting concurrent trends-rising competition and collaboration across and within nations: If countries continue to fund most scientific research, (international) collaborations among scientists across levels and teamwork in diverse types of research organizations have facilitated remarkable growth in knowledge production (Adams, 2013; Powell, Baker et al., 2017). The future of (higher) education and science that must grapple with complex environmental and social problems now depends on how we (re)organize these fields to become more collaborative in the face of globalized competition between teams, organizations, and countries.

\section{Transnationalization of Higher Education and Science via "Brain Circulation"}

Transnationalization (and regionalization) of higher education and science challenge traditional nation-based studies. The diffusion of worldwide ideas and norms in science is a powerful driver of global similarities, as no country can resist global standards (Drori, Meyer, Ramirez, \& Schofer, 2003). Higher education participation rates continue to climb, now reaching large proportions of each cohort in societies everywhere (Schofer \& Meyer, 2005). Scientization is significantly driven by the research universities that increasingly influence the design of reforms of schooling, policymaking activities, and economic development-by producing expertise via professionals and, ultimately, the occupations of the future (Baker, 2014). Despite convergence pressures, directed by international organizations, such as UNESCO and the OECD, comparative institutional analyses show persistent differences in the structuring and capacity for innovation of higher education and science systems. We find sustained, even increasing, significance of the research university in scientific production across countries (Powell \& Dusdal, 2017).

While industry and science-producing organizational forms such as independent research institutes, hospitals, government agencies, academics, and museums, among others, contribute to advancing knowledge, we know too little about the conditions these forms, and organizational hybrids, provide (Dusdal, 2018). Institutionally, university, industry, and government form the "triple helix" of science production, with specific developments 
of these interinstitutional, boundary-spanning networks leading to different innovation dynamics (Leydesdorff \& Etzkowitz, 1998). If the key organizational form remains the university, with its tremendous capacity for transferring knowledge intergenerationally, between disciplines, and across cultural boundaries, then research must delve deeper into the learning opportunities, networks, and types of collaboration this central organizational form enables. The main driver of scientific capacity is the education and training of each generation of scientists poised to push the cutting edge.

Factors, from research policy and funding instruments and system development to scientific communication, have also transformed the ways science is conducted and the scope and speed of knowledge diffusion around the world. If markets for scientific talent have always been wide, today they are nearly boundless, at least at the peaks and given fluency in the dominant English as the contemporary lingua franca. Elaborate migratory flows, massive government and philanthropic programs, and everyday mobility enormously facilitate the exchange that leads to scientific networks, "brain circulation", and the potential for collaboration on a vast scale (Sugimoto et al., 2017). For example, the European Union's Erasmus program or the US Fulbright Fellowships have enabled millions of students and faculty to visit other universities to broaden their horizons and explicitly collaborate interculturally. Yet the social sciences remain stubbornly parochial in the face of cultural diversity and massive global challenges, with the university's contribution to knowledge unquestionable, but underspecified and underappreciated (Stevens, Miller-Idriss, \& Shami, 2018).

Throughout history, large-scale migration flows, especially of elites, have led to the transfer of ideas across cultural, linguistic, and geographical borders. States, foundations, and international organizations have systematically increased educational exchange and mobility of scientists and students. These trends are more than symbolically significant, as border crossings transform individual careers and epistemic networks. Yet such opportunities remain highly stratified along such lines as class and gender, despite transnational higher education and mobility having witnessed tremendous growth (Zippel, 2017). This globalization manifests itself in joint, dual, or franchised programs, online and distance education, and international branch campuses, with research developing apace (Kosmützky \& Putty, 2016). What will be the consequence of these elite border-crossings in the face of humanitarian crises of restricted migration and mobility, such as waves of refugees and newly constructed walls between countries? Indeed, those responsible for governance of global, regional, and national systems face a crisis of legitimation that challenges higher education and science in their traditional means of generating expertise (Kennedy, 2015). Thus, 
amid calls for more "relevance" and "impact," the governance by and of science must address the age-old inequalities, new subjectivities, and the gaps between research, policies, and practices. Not only for scientists in countries experiencing rising nationalism, mobility is far from luxury, but rather sustains academic life. Fundamentally, in complex globe-spanning higher education and science systems, the diffusion of ideas and mobility of scholars is necessary for innovation and influence. The strongest science systems are open: those with most international co-authorship and highest mobility of the research workforce, with smaller countries, such as Switzerland and Singapore, excelling (Wagner \& Jonkers, 2017).

\section{InFormation \& COMmUnication TeCHNOLOGY}

Yet even without the growth of spatial mobility, the revolution spurred by information and communication technology (ICT) has quickened learning processes and scientific work. Networked computers (and big data) have significantly increased the power of diverse methodologies to explore and explain. They reduce barriers to collaboration across boundaries, cultural and hierarchical (Leahey, 2016). Applications of ICT have raised productivity and made peer review and publication faster and less costly. However, networked computers are not solely a technological intervention, but rather a developmental task requiring social learning to ideally combine both technological and social capabilities (Hanna, 2010). Many disciplines are in the midst of paradigm shifts in their processes of peer review and publication.

\section{Languages, Academic Cultures, and Machine Learning}

Albeit with large field-specific differences, language remains a barrier to understanding and the sharing of research problems and findings. Whereas humanities scholars and social scientists remain more-or-less dedicated to their national languages, the natural sciences now publish their crucial findings in English-language journals. The scientific lingua franca has shifted from French to German to English over the past two centuries. Translation devices applying the tools of computational linguistics and artificial intelligence are poised to radically facilitate the transfer of ideas. Machine learning may reduce the advantages that Anglophone scientists have long enjoyed. As scholarship becomes increasingly accessible, also to those outside the academy and in diverse cultural contexts, further transformations are likely.

Yet not only the languages of science pose a barrier to universal collaboration. Academic, intellectual styles go far beyond language itself to affect relative foci on paradigm-development, on description or explanation, 
and on commentary; all with varying modes of interaction (Galtung, 1981). Among the determinants for successful (international) collaboration are team characteristics, worldviews and motivations, and collaboration processes. Long-term collaborations that combine formal and informal interactions between researchers may remain creative and productive for decades. The basis for productive collaborative networks are the preexisting relationships of the involved researchers and organizations, repeated interactions, and intellectual affinities (Ulnicane, 2015). Policymakers could bolster organizations to support such networks. Researchers could analyze collaboration in multicultural teams and the conditions for an optimal sharing of expertise-minimizing misunderstandings and conflicts-since compositional diversity in research teams has positive and negative effects on teamwork.

\section{Scientific Peer Review and Publication}

A further driver of change that reshapes both competition and collaboration is innovation in forms of peer review and scientific publication formats, especially open access digital publication. The standards and processes of scientific exchange and publishing are challenged by the rapid diffusion of knowledge through networks using ICT. This stands in contrast to the incremental and time-consuming process of writing grant applications, peer review, and official publication as standards of scientific practice (Lamont, 2009). Changing publication strategies at individual and organizational level also reflect the rise of research evaluation, excellence initiatives, thematic programs, and ratings and rankings.

\section{Policy Learning, Comparisons, and Supranational Coordination}

The influence of internationally acknowledged ideas, norms, and standards (best practices) manifests itself at various levels. Once change is acknowledged as desirable, policies are mediated by the politics of borrowing practices. Systematic international exchange enhances policy learning, in turn increasingly affected by global competition in education and labor markets. In some regions, supranational coordination further strengthens such diffusion.

At the forefront of social and economic change and nation-state development, education, and science systems foster and reflect major societal shifts even as they exhibit persistent cultural particularities. Learning from leaders has always been significant as countries compete for cultural and economic power. Yet global transformations in higher education and science have made the supranational level and cross-national comparisons even 
more significant, with regional embeddedness also substantial. Ambitious targets for R\&D spending (3\% of GDP for EU countries by 2020) exist simultaneously with rampant privatization and marketization of (higher) education. Part of what has been called the "competition fetish" (Naidoo, 2016) at various levels reflects competition between individual scholars for scarce resources, from research funding to reputation; competition between corporations, many of which rush to enter the burgeoning private market for educational services; and competition between states for dominance via global university brands. This occurs even as universities increasingly seek to distinguish themselves through sophisticated identity campaigns, competing for students, and research funds via market placement in stratified higher education systems (Drori, Delmestri, \& Oberg, 2013).

Today, competitiveness is continuously monitored by comparative indicators used by policymakers, scholars, and administrators to generate reform goals, to identify standards and best practices, and to empirically verify policies and programs. Increasingly, countries have enacted policies that emulate-or are legitimated by reference to-successful foreign models. Mechanisms of such cross-cultural transfer include "continuous competitive comparison" in such forms as rankings, benchmarking, and best practices; policy learning and networks; and intergovernmental negotiation and supranational coordination. All of these unfold their positive and negative effects at the nexus of collaboration and competition.

For centuries, only a few regional centers of learning were highly influential, depending on economic and cultural power, as on linguistic dominance. Today, based on quantitative and qualitative indicators, universities in many countries compete worldwide for talent, funding, and prestige. If most universities have little chance of succeeding to become preeminent, overall the academic drift in higher education that combines teaching and research missions has resulted in rising credential levels and broadened science capacity. Two hundred countries now contribute to scientific knowledge production in leading peer-reviewed journals. If "continuous competitive comparison" both within and between countries creates winners and losers, more than ever universities and scientific communities are linked globally, via communication networks, conferences, and exchanges, answering competitive pressures with collaboration.

In the policy arena, international organizations, such as UNESCO, the OECD, or the World Bank, have become actively engaged in producing and utilizing academic outputs to facilitate policy transfer and spur development, identifying the most difficult problems humanity faces. With differences in influence depending on past colonial relationships, languages, and politics, leading countries in education and science worldwide, including Germany, the United States, and China, have differentially developed 
their higher education and science systems. Policymakers continue to look across borders for inspiration, guidance, or practices as they reform education and science to sustain or increase their competitiveness.

Recently, supranational coordination facilitates the definition of standards, extends cross-border mobility, and enables collaboration. In education and training, the open method of coordination now stretches far beyond the European Union in engaging countries in reform initiatives, such as the Bologna process in higher education, and funding instruments, such as the EU Framework Programme for Research and Innovation (currently: Horizon 2020; nearly $€ 80$ billion of funding, 2014-2020). Through standardization, mobility, and transparency, supranational coordination relies on a range of instruments to strengthen European competitiveness.

\section{Governance: From R\&D Investments to Evaluation}

In an era in which accountability and evaluation are ubiquitous, the governance of higher education and science is based on explicitly measured and evaluated outputs, mainly research articles. The effects and changed behavior of individuals and organizations in such regimes has garnered attention, yet few longitudinal studies show the long-term impact thereof on universities and research. Worldwide, research evaluation systems share the rationale of financial accounting that spreads and entrenches certain values and techniques aiming to foster enhanced performance and achieve efficiency in science (Whitley \& Gläser, 2007). Such attempts to transform qualities into numeric forms to measure, to compare, and to inform decision-making reduce the quality of information and threaten to narrow the recognition and impact of knowledge generated in diverse systems.

Many countries aim to improve the quality of higher education through research evaluation. The first such system, the UK's Research Assessment Exercise (RAE) from 1986, now the Research Excellence Framework (REF), has become increasingly formalized and standardized over time, with attempts to make it transparent and react to critiques of its myriad (un)intended consequences, including selective submission behavior of departments (Marques, et al., 2017): In the multidisciplinary field of educational research, for example, there have been decreases in the number of academic staff whose research was submitted for peer review assessment; the research article has become the preferred publication format; quantitative analyses have been bolstered; and stable concentration of funding among top departments maintains stratification and exacerbates departmental disparities. Such discipline-specific studies emphasize how research evaluation impacts the structural organization and cognitive development 
of disciplinary research, reinforcing stratification, and standardization (see Hamann, 2016 on history). Such systems reflect the changing relationships between states and universities and other research organizations. The consequences of such new forms of governance are often intentional, yet many unanticipated or unintentional results also follow. Analysis is needed to chart these effects in various disciplines and on different levels.

Hardly escapable mechanisms in efforts to account for the quality of higher education systems, ratings and rankings increasingly shape the status and reputation of national systems, of organizations, and of researchers affiliated with particular organizations and units within them. Research shows myriad effects of these evaluations of "quality" for organizations and individuals as research outputs are quantified (Espeland \& Sauder, 2016). Often framed in terms of New Public Management, higher education organizations are forced to become more accountable through such mechanisms, whatever such measurements' shortcomings. Studies could address the interconnections and conversions and chart the consequences. How do research organizations actively construct and apply such competitive measures in their attempts to secure achieved status or strive for higher reputation within regionally, nationally, and globally stratified higher education and science systems?

\section{Governance Through Programmification}

In many countries, governance has evolved within differentiating systems and through increasing R\&D investments. Ministries and other government agencies increase their influence on research agendas through the proliferation of specifically defined thematic programs (Zapp, et al., 2018). Such "programmification" symbolizes more educated policymakers and administrators with the aspiration to guide scientific development and target resources in the hopes of facilitating innovation. On the other hand, especially when such funding lines question or substitute for infrastructure, subvert peer review or reduce scientific autonomy, such programs may counter necessary long-term commitments to fundamental research and scientifically driven priorities. Viewed globally, these programs also lead to interpretation and adoption of global and regional ideas and norms, a force for enhanced exchange and isomorphism. Yet such narrowing of research focus also poses risks of overinvestment in fashionable topics or commitment to certain research questions with policy relevance to the detriment of a diverse scientific agenda or guarantees of autonomy needed for blue sky or high-risk research that promises pioneering insights.

Along with unprecedented structural expansion of higher education to facilitate the "knowledge society," the perceived importance of 
evidence-based policymaking and notions of quality, excellence, relevance, and impact has risen (Zapp et al., 2018). Government-funded R\&D and research councils' substantial growth in both funding and large-scale, long-term planning, including thematic choices, are evidence of such "programmification". If the importance of external models has grown in an era of transnationalization, translation occurs at every governance level, resulting in specific research models and priorities across societies. Researchers study such diffusion of ideas, norms, and policies in an era of stark competition and rising collaboration. While the potential for collaborations may indeed grow with proliferation of such thematic research programs, the tools required to coordinate such complex research projects worldwide thus far exist more in certain fields, often those requiring enormously costly facilities, such as quantum physics or astronomy. Indeed, the Internet was devised to facilitate exactly such globe-spanning scientific collaboration (Berners-Lee, 2018).

Science and policymaking have become increasingly intertwined, resulting in new challenges of authority and conflicts over research priorities and output measurements. For science studies, this increases the necessity to attend to the complexities of a dynamic relationship in which boundary-spanning managers gain influence as they translate across this divide. Not only are different conceptualizations of disciplinary research and development across countries and regions crucial to analyze, but also the distinct legacies thereof. For example, the distinct, expansive role of the EU in constructing a European Research Area, in establishing cross-border networks, and in shaping research agendas shows how supranational governance simultaneously offers incentives and puts pressure on national and local actors to align their research to overarching priorities and themes-and collaborate interculturally. Over the past several decades, political interest in evidence-based policy-making, quality assessment, and research evaluation, and direct involvement of various decision-makers has led to the establishment of new organizations, funding instruments, programs, and training programs. Often, such developments challenge old paradigms, disciplinary divisions of labor, and boundaries between science and policy.

\section{FUTURE RESEARCH DIRECTIONS}

Higher education and scientific production have been analyzed by various established fields, including bibliometrics, sociology of higher education, and science studies. Challenges include disciplinary divisions of labor; data selectivity and methodological nationalism; lack of synthesis; and few longitudinal analyses. In-depth comparative research is needed to extend our knowledge beyond dominant science-producing regions and countries and improve our understanding of cultural and disciplinary diversity. 
Yet science viewed as a complex and continuously evolving network of individuals, teams, projects, ideas, and publications demands innovative research (see Leahey, 2016).

In terms of data and methods, the science of science uses more and better data (and calculation capacity) to explore developments in scholarly inputs and outputs, from funding and collaborations to production and evaluation (Fortunato et al., 2018). Together with big data, multi-level and mixed methods approaches extend the possibilities for analysis and explanation. For example, network analysis and shifts away from linear causality toward complexity promise innovation, yet here too the overreliance on a few global databases (quantitative) and a few countries (qualitative) produces a selective and culturally biased picture of global scientific capacity and output. This also reproduces stratification-detrimental to the diffusion of ideas.

The evolution of journal publications since 1900 shows major shifts in the global, regional, and national development of higher education and science systems. The remarkable expansion of science reflects contrasting and simultaneous trends: rising competition at all levels matched by diverse forms of collaboration among scientists working in different disciplinary contexts, countries, and organizational forms. The future of science is indeed global, but much research remains parochial and particularistic. Thus, more internationally and interculturally comparative research is warranted, especially on the global flows of researchers and ideas. Governance via international organizations, supranational coordination, and evaluation systems are increasingly studied, but risk reifying stratification patterns within higher education and science.

Transdisciplinary collaborations among individual scientists, research teams, and organizations-across national and linguistic borders-demand enhanced attention, epecially to understand conditions and consequences (Lee \& Bozeman, 2005). Analyses of interactions between institutions (economy, politics, and society) and organizational forms and their respective networks promise insights into contemporary competition and collaboration patterns. Opportunities for mobility (brain circulation) and collaboration as well as ICT and open access publication formats are among the key drivers of pure exponential growth scientific output globally. Yet forms of peer review, research evaluation, and publication lag behind in representing fully the complexity of scientific exchange or the diversity among research outputs and their impacts.

The establishment and maintenance of truly global scientific networks responsible for addressing many of the most crucial scientific puzzles will be an increasingly crucial topic. Given their ascendant importance, international, transdisciplinary, and intersectoral collaborations deserve 
encompassing studies. If higher education and research policies are to optimally promote scientific productivity and innovation, such interventions should be developed upon deeper understanding of the drivers and dynamics of types of research collaboration. Future research will explore the organizational and network conditions that facilitate collaborations and thus the science with most influence and impact.

\section{REFERENCES}

Adams, J. (2013). Collaborations: the fourth age of research. Nature, 497(7451), 557-560.

Baker, D. P. (2014). The schooled society. Stanford, CA: Stanford University Press.

Beaver, D. D. (2001). Reflections on scientific collaboration (and Its study). Scientometrics, 52(3), 365-377.

Berners-Lee, T. (2018). History of the web. Retrieved from https://webfoundation. org/about/vision/history-of-the-web (accessed June 02, 2018).

Bozeman, B., \& Boardman, C. (2014). Research collaboration and team science. Dordrecht, The Netherlands: Springer.

de Solla Price, D. J. (1986). Little science, big science ... and beyond. New York, NY: Columbia University Press.

Drori, G. S., Delmestri, G., \& Oberg, A. (2013). Branding the university: Relational strategy of identity construction in a competitive field. In L. Engwall \& P. Scott (Eds.), Trust in higher education institutions (pp. 134-147). London, UK: Portland Press.

Drori, G. S., Meyer, J. W., Ramirez, F. O., \& Schofer, E. (2003). Science in the modern world polity. Stanford, CA: Stanford University Press.

Dusdal, J. (2018). Welche Organisationsformen produzieren Wissenschaft? Frankfurt/Main, Germany: Campus.

Espeland, W., \& Sauder, M. (2016). Engines of anxiety. New York, NY: Russell Sage Foundation.

Fortunato, S., Bergstrom, C. T., Börner, K., Evans, J. A., Helbing, D., Milojević, S., Petersen, A. M., Radicchi, F., Sinatra, R., Uzzi, B., Vespignani, A., Waltman, L., Wang, D., \& Barabási, A.-L. (2018). Science of science. Science, 359, eaao0185. doi:10.1126/science.aao0185.

Galtung, J. (1981). Structure, culture and intellectual style. Social Science Information, 20(6), 817-856.

Hamann, J. (2016). The visible hand of research performance assessment. Higher Education, 72(6), 761-779.

Hanna, N. K. (2010). Transforming government and building the information society. Heidelberg, Germany: Springer.

Jeong, S., Choi, J. Y., \& Kim, J.-Y. (2014). On the drivers of international collaboration. Science and Public Policy, 41(4), 520-531.

Katz, J. S., \& Hicks, D. (1997). How much is a collaboration worth? Scientometrics, 40(3), 541-554. 
Katz, J. S., \& Martin, B. R. (1997). What is research collaboration? Research Policy, 26(1), 1-18.

Kennedy, M. D. (2015). Globalizing knowledge. Stanford, CA: Stanford University Press.

Kosmützky, A., \& Putty, R. (2016). Transcending borders and traversing boundaries. Journal of Studies in International Education, 20(1), 8-33.

Lamont, M. (2009). How professors think. Cambridge, MA: Harvard University Press.

Leahey, E. (2016). From Sole Investigator to Team Scientist: Trends in the Practice and Study of Research Collaboration. Annual Review of Sociology, 42, 9.1-9.20. DOI: 10.1146/annurev-soc-081715-074219

Lee, S., \& Bozeman, L. (2005). The impact of research collaboration on scientific productivity. Social Studies of Science, 35(5), 673-702.

Leydesdorff, L., \& Etzkowitz, H. (1998). The triple helix as a model for innovation studies. Science and Public Policy, 25(3), 195-203.

Marques, M., Powell, J. J. W., Zapp, M., \& Biesta, G. (2017). How Does Research Evaluation Impact Educational Research? Exploring Intended and Unintended Consequences of Research Assessment in the United Kingdom, 1986-2014. European Educational Research Journal, 16(6), 820-842.

Mosbah-Natanson, S., \& Gingras, Y. (2013). The globalization of social sciences? Current Sociology, 62(5), 626-646.

Naidoo, R. (2016). The competition fetish in higher education. British Journal of Sociology of Education, 37(1), 1-10.

Powell, W. W. (1998). Learning from collaboration. California Management Review, 40(3), 228-240.

Powell, J. J. W., Baker, D. P., \& Fernandez, F. (Eds.) (2017). The century of science: The global triumph of the research. Bingley, UK: Emerald.

Powell, J. J. W., \& Dusdal, J. (2017). Research organizations' contribution to publications in science and technology disciplines in Germany, France, Belgium, and Luxembourg. Minerva, 55, 413-434.

Powell, J. J. W., Fernandez, F., Crist, J. T., Dusdal, J., Zhang, L., \& Baker, D. P. (2017). Introduction: The worldwide triumph of the research university and globalizing science. In J. J. W. Powell, D. P. Baker \& F. Fernandez (Eds.), The century of science: The global triumph of the research university (pp. 1-36). Bingley, UK: Emerald.

Schofer, E., \& Meyer, J. W. (2005). The worldwide expansion of higher education in the twentieth century. American Sociological Review, 70(6), 898-920.

Stevens, M. L., Miller-Idriss, C., \& Shami, S. (2018). Seeing the world: How US universities make knowledge in a global era. Princeton, NJ: Princeton University Press.

Sugimoto, C. R., Robinson-Garcia, N., S. Murray, D., Yegros-Yegros, A., Costas, R., \& Larivière, V. (2017). Scientists have most impact when they're free to move. Nature, 550, 29-31.

Ulnicane, I. (2015). Why do international research collaborations last? Science and Public Policy, 42(4), 433-447.

Wagner, C. S. (2005). Six case studies of international collaboration in science. Scientometrics, 62(1), 3-26. 
Wagner, C. S., \& Jonkers, K. (2017). Open countries have strong science. Nature, 550, 32-33.

Whitley, R., \& Gläser, J. (2007). Changing governance of the public sciences. In R. Whitley \& J. Gläser (Eds.), The changing governance of the sciences (pp. 3-27). Heidelberg, Germany: Springer.

Wuchty, S., Jones, B. F., \& Uzzi, B. (2007). The increasing dominance of teams in production of knowledge. Science, 316(5827), 1036-1039.

Zapp, M., Marques, M., \& Powell, J. J. W. (2018). European educational research (re)constructed. Oxford, UK: Symposium Books.

Zippel, K. (2017). Women in global science: advancing academic careers through international collaboration. Stanford, CA: Stanford University Press.

Justin J.W. Powell is Professor of Sociology of Education at the University of Luxembourg. His comparative institutional analyses chart persistence and change in special and inclusive education, in vocational training and higher education, and in science systems and research policy. His award-winning books include Barriers to Inclusion: Special Education in the US and Germany (Routledge, 2011/2016), Comparing Special Education: Origins to Contemporary Paradoxes (Stanford University Press, 2011), and The Century of Science: The Global Triumph of the Research University (Emerald, 2017).

\section{RELATED ESSAYS}

The Development of Expertise in Scientific Research (Education), David F. Feldon

Expertise (Sociology), Gil Eyal

The Evidence-Based Practice Movement (Sociology), Edward W. Gondolf

The Role of Data in Research and Policy (Sociology), Barbara A. Anderson

Rationalization of Higher Education (Sociology), Tressie McMillan Cottom and Gaye Tuchman

State of the Art in Competition Research (Psychology), Márta Fülöp and Gábor Orosz

The Institutional Logics Perspective (Sociology), Patricia H. Thornton et al.

Can Public Policy Influence Private Innovation? (Economics), James Bessen

Complexity: An Emerging Trend in Social Sciences (Anthropology), J. Stephen

Lansing

Globalization of Capital and National Policymaking (Political Science), Steven R. Hall

Culture and Globalization (Sociology), Frederick F. Wherry

Virtual Worlds as Laboratories (Methods), Travis L. Ross et al.

Culture and Social Networks (Sociology), Jan A. Fuhse

Higher Education: A Field in Ferment (Sociology), W. Richard Scott

To Flop Is Human: Inventing Better Scientific Approaches to Anticipating 
Failure (Methods), Robert Boruch and Alan Ruby

Meta-Analysis (Methods), Larry V. Hedges and Martyna Citkowicz

Creativity in Teams (Psychology), Leigh L. Thompson and Elizabeth Ruth Wilson

Ethical Decision-Making: Contemporary Research on the Role of the Self (Psychology), Lisa L. Shu and Daniel A. Effron

Rationalization of Higher Education (Sociology), Tressie McMillan Cottom and Gaye Tuchman

Misinformation and How to Correct It (Psychology), John Cook et al.

The Development of Social Trust (Psychology), Vikram K. Jaswal and Marissa B. Drell

Translational Sociology (Sociology), Elaine Wethington 